\title{
Mathematic Model of Heat Transport in Materials During CutTing Process
}

\author{
Dagmar Janacova ${ }^{\mathrm{a}}$, Pavel Mokrejs ${ }^{\mathrm{b}}$, Vladimir Vasek $^{\mathrm{a}}$, Rudolf Drga $^{\mathrm{a}}$, \\ Ondrej Liska ${ }^{\mathrm{c}}$, Jiri Krenek ${ }^{\mathrm{a}}$
}

\author{
${ }^{a}$ Department of Automatic and Control Engineering, Faculty of Applied Informatics, Tomas Bata University in Zlin \\ ${ }^{b}$ Department of Polymer Engineering, Faculty of Technology, Tomas Bata University in Zlin \\ Nám. T. G. Masaryka 5555, 76001 Zlín, Czech Republic \\ ${ }^{c}$ Department of Automation, Control and Human Machine Interaction
}

Faculty of Mechanical Engineering, Technical University of Košice, Letná 9, 04200 Košice, Slovak Republic

\begin{abstract}
Printed circuit boards (PCBs) that represent a significant part of electronic waste are potential sources of material and energy. In the paper we focused on study of a cutting as an alternative method of conductive ways separating from plastic board as one of stages of the printed circuit board recycling procedure. High velocity of cutting belt is connected with enormous heat production. Due to the generation of high temperatures may lead to caking of separated components of metal and plastic materials. For this reason we formulated mathematic model of the cutting process and on the base we can determine of temperature fields in PCB materials during cutting. Of courses of them we can calculate the heat intensity and consequently the critical velocity of cut ting belt without damage of PCB materials.
\end{abstract}

Keywords: Cutting; Mathematical Modeling; Printed Circuit Board; Separation; Recycling; Heat Transport
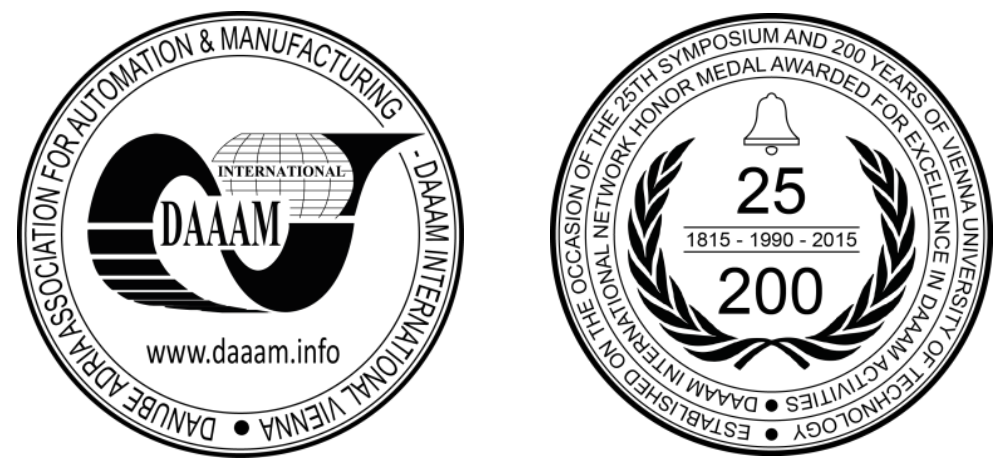

This Publication has to be referred as: Janacova, D[agmar]; Mokrejs, P[avel]; Vasek, V[ladimir]; Drga, R[udolf]; Liska, O[ndrej] \& Krenek, J[iri] (2016). Mathematic Model of Heat Transport in Materials During Cutting Process, Proceedings of the 26th DAAAM International Symposium, pp.0035-0039, B. Katalinic (Ed.), Published by DAAAM International, ISBN 978-3-902734-07-5, ISSN 1726-9679, Vienna, Austria DOI:10.2507/26th.daaam.proceedings.005 


\section{Introduction}

Recycling electronic waste is due to the ever increasing trend of computer technology in households and companies is becoming one of the major challenges of the 21 st century. There are many methods to handle these waste. However, particularly in the processing and recycling of printed circuit board technology faces many due to the use of chemical substances with environmental issues (waste water, poisons). Therefore possibilities of PCBs reuse are searched in the whole world. Material composition of PCBs is highly heterogeneous. They are made of plastic boards covered by one or more metal layers with moulded. Suitability of the above mentioned materials for their reuse strongly depends on economy costs. For this purpose, we search energy-saving technological method of the conductive ways from plastic boards separation. In this paper we focused on study of a cutting as an alternative method of conductive ways from plastic board separation as one of stages of the printed circuit board recycling process.

\section{PCB recycling}

In general, there are many problems by PCB recycling at this time the mechanical-physical processes are attracting more attention than chemical operations in that considerable chemical waste water polluted by hazardous chemical substances is produced. By reason of an effective recycling of precious metals and other valuable raw materials, melting and electrolysis are preferable than mechanical recycling methods. Furthermore, the polluting matters are removed from $\mathrm{PCB}$ by melting and electrolysis. On the other hand, the thermic methods seem as best environmentally $[1,4]$.

\subsection{Processes of the PCB recycling}

As it was mentioned in previous section, cutting represents an alternative method of conductive ways from plastic board separation as one of stages of the printed circuit board recycling process [1,2].

In practice, the cutting process can be realized by using of an band saw. The process course depends on many factors.

Non-stationary temperature field in PCB and cutting belt can be described by equations (1) - (6).

Heat transport in the plastic board describes Fourier-Kirchhoff's law [7]

$$
\frac{\partial t_{1}(x, \tau)}{\partial \tau}=a_{1} \frac{\partial^{2} t_{1}(x, \tau)}{\partial x^{2}} \quad \tau>0 ; 0<x<\infty
$$

Analogously, equation (2) describes transport of heat in the saw band describes Fourier-Kirchhoff's law

$$
\frac{\partial t_{1}(x, \tau)}{\partial \tau}=a_{1} \frac{\partial^{2} t_{1}(x, \tau)}{\partial x^{2}} \quad \tau>0 ;-\infty<x<0
$$

Initial temperature distribution in the belt and in the board is given by equation (3)

$$
t_{1}(x, 0)=t_{2}(x, 0)=t_{p}
$$

Heat transport in the touch point of both materials is given by equation (5).

$$
t_{1}(\infty, \tau)=t_{2}(-\infty, \tau)=t_{p}
$$

Heat transport in the touch point of both materials is given by equation (5) [6].

$$
q+\lambda_{1} \frac{\partial t_{1}(0, \tau)}{\partial x}-\lambda_{2} \frac{\partial t_{2}(0, \tau)}{\partial x}=0
$$

Equation (6) determines change of temperature in infinite points of the belt and in the board.

$$
\frac{\partial t_{1}(\infty, \tau)}{\partial x}=0 \quad \frac{\partial t_{2}(-\infty, \tau)}{\partial x}=0
$$

We supposed that total heat flow divides equally among board and the cutting belt

$$
q_{1}=q_{2}=0.5 q
$$


Under these conditions we obtained analytical solution given by temperature field $\mathrm{t} 1(\mathrm{x}, \tau)$ in plastic board $[1,8]$

$t_{1}(x, \tau)=\frac{2 q}{\lambda_{1}} \sqrt{a_{1} \tau}\left[\frac{\mathrm{e}^{-\frac{x^{2}}{4 a_{1} \tau}}}{\pi}-\frac{x}{2 \sqrt{a_{1} \tau}} \cdot \operatorname{erfc}\left(\frac{x}{2 \sqrt{a_{1} \tau}}\right)\right]$

List of symbols:

a - thermal diffusivity, $\left[\mathrm{m}^{2} \cdot \mathrm{s}^{-1}\right]$;

$\delta$ - thickness of board, $[\mathrm{m}]$

$\mathrm{c}_{\mathrm{p}^{-}} \quad$ specific thermal capacity, $\left[\mathrm{J} \cdot \mathrm{kg}^{-1} \cdot \mathrm{K}^{-1}\right]$;

q - heat flow intensity, [W.m-2];

t - temperature, $\left[{ }^{\circ} \mathrm{C}\right]$;

$\mathrm{X}^{-} \quad$ position coordinate, $[\mathrm{m}]$;

$\lambda$ - thermal conductivity, $\left[\mathrm{W} \cdot \mathrm{m}^{-1} \cdot \mathrm{K}^{-1}\right]$;

$\rho$ - density, $\left[\mathrm{kg} \cdot \mathrm{m}^{-3}\right]$

$\tau-\quad$ time, $[\mathrm{s}]$.

\begin{tabular}{cr}
\hline $\mathrm{x}[\mathrm{m}]$ & $\mathrm{t}\left[{ }^{\circ} \mathrm{C}\right]$ \\
\hline 0.0000 & 177.180 \\
0.0002 & 132.768 \\
0.0004 & 94.181 \\
0.0006 & 64.449 \\
0.0008 & 44.133 \\
0.0010 & 31.824 \\
0.0012 & 25.211 \\
0.0014 & 22.060 \\
0.0016 & 20.230 \\
0.0018 & 20.203 \\
0.0020 & 20.065 \\
\hline
\end{tabular}

1. Calculated temperature

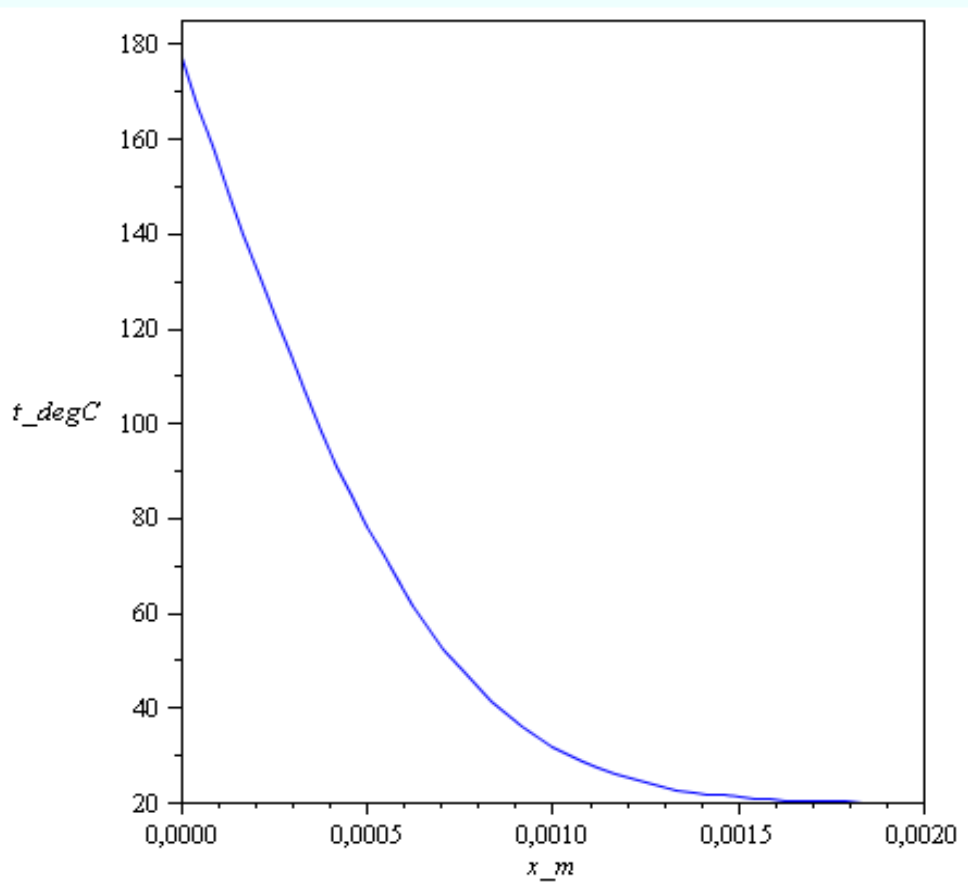

Fig. 1. Temperature field in during cutting in PCB with thickness $2 \mathrm{~mm}$ 
Parameters for the calculating $[4,7,9]$ :

Thermal conductivity $\lambda: 0.205 \mathrm{~W} . \mathrm{m}^{-1} \cdot \mathrm{K}^{-1}$, Time of the process $\tau: 40 \mathrm{~s}$, Density $\rho: 1200 \mathrm{~kg} \cdot \mathrm{m}^{-3}$, Specific thermal capacity $\mathrm{c}_{\mathrm{p}}: 1040 \mathrm{~J} \cdot \mathrm{kg}^{-1} \cdot \mathrm{K}^{-1}$, Thickness of PCB $\delta 2 \mathrm{~mm}$, Heat transfer $\alpha: 6000 \mathrm{~W} . \mathrm{m}^{-2} \cdot \mathrm{K}^{-1}$ Thermal diffusivity: $a: 1.6410^{-5} \mathrm{~m}^{2} . \mathrm{s}^{-1}$

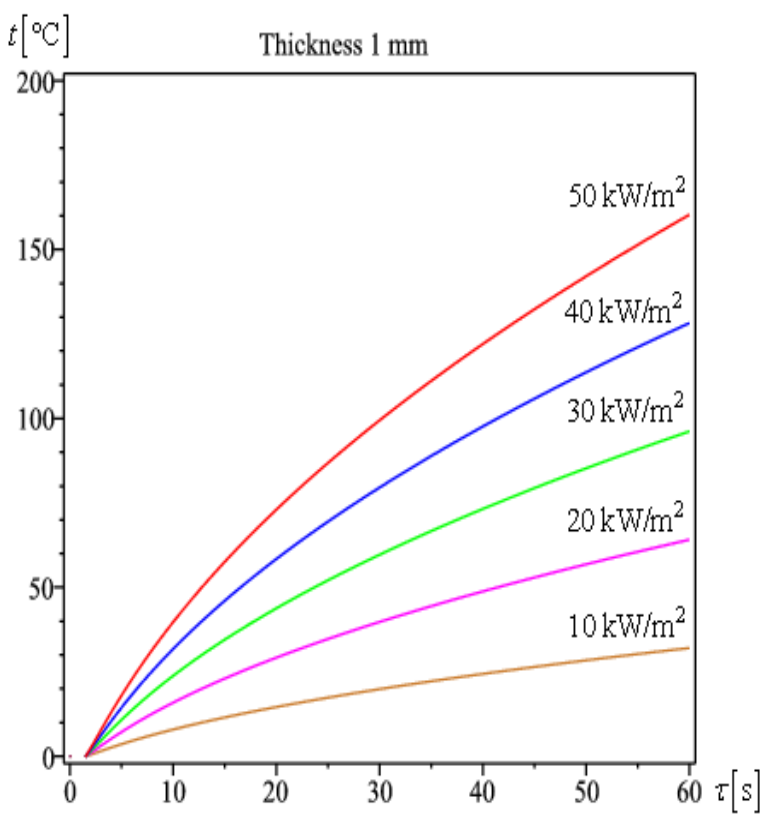

Fig. 2. Increase of temperature in PCB in dependence on supplied heat flow intensity for variable velocity of cutting belt

\section{Conclusion}

We interesting by the optimal solution recycling printed circuit boards minimizing environmental impact. A proper solution in that respect technological procedure of cutting circuit boards and subsequent separation disintegrated recycled material which is due to high temperatures due to the friction of the sintering of precious metals and ultimate recycling process that greatly complicate. The critical temperature at which sintering occurs between plastic and metal is around $160{ }^{\circ} \mathrm{C}$. When modeling of unsteady temperature fields is largely adversely affected by contact pressure $\mathrm{p}$ during cutting to increase at a disproportionately increased the total heat flow intensity q. Great influence on the course of thermal field has thermal conductivity and which is for example a change of one order of magnitude above showed at time $5 \mathrm{sec}$, three times greater temperature rise [5,9]. The most noticeable temperature increase is noticeable on the edges of the board. The critical temperature is reflected due to the relatively short time constants, only at a distance $\mathrm{x}$ of the order of tenths of a millimeter from the point of contact with the cutting wheel. Excessive heating here arises due to high friction coefficient and the contact pressure $\mathrm{p}$. Conversely with increasing distance $\mathrm{x}$ from the point of contact of the cutting, the temperature stabilizes and approaches the surface temperature. When extreme values when the time constant is in the tens of seconds, is maintained in all simulated cases resulting in the destruction components.

We determined friction coefficient, thrust pressure and frequency of the cutting belt rotation as major factors that affect generated heat flow. In consequence of so much of heat generation during the process, the plastic material can agglomerate with metals, which complicates the process. On the base of suggested mathematical model we can to determine velocity of cutting belt which depends on a thermal properties of PCB materials.

Acknowledgements

This work was performed with financial support of research project NPU I No. MSMT-7778/2014 by the Ministry of Education of the Czech Republic, by the Technology Agency of the Czech Republic as a part of the project called TA03010724 AV and EV LED luminaire with a higher degree of protection and also by the European Regional Development Fund under the Project CEBIA-Tech No. CZ.1.05/2.1.00/03.0089.

\section{References}

[1] Janacova, D. Vasek, V., Mokrejs, P., Krenek, J., Drga, R.. (2011). Temperature fields solving in two-layer plate with Comsol Multiphysics software, Proceedings of the 22nd DAAAM International World Symposium, 22-23th November 2011, Vienna, Katalinic, B. (Ed.), Published by DAAAM International, Vienna. 
[2] Charvatova, H. (2010) Modelling of grinding process by printed circuit boards recycling, DAAAM International Vienna, Proceedings of the 21st International DAAAM Symposium Intelligent Manufacturing \& Automation, 475-476, ISBN-ISSN 978-3-901509-73-5.

[3] Sykorova, L.; Suba, O., Malachova, M., Cerny, J. (2011) Temperature Field Simulation of Polymeric Materials During Laser Machining Using COSMOS / M Software, Proceedings of 13th WSEAS International Conference on Automatic control, modelling \& simulation (ACMOS'11), WSEAS Press, Lanzarote, Canary Islands.

[4] Janacova, D. Kolomaznik, K., Vasek, V., Krenek, J. (2007). "Separation of Printed Circuit Board by Temperature Shock", Proceedings of the 5th WSEAS Conference on Heat Transfer, Thermal Engineering and Environment HTE'07, WSEAS (Ed.). August 25 - 27, 2007, Athens.

[5] Vasek, L., Dolinay, V. (2010). „Simulation Model of Heat Distribution and Consumption in Municipal Heating Network", in 14th WSEAS International Conference on Systems. Latest Trends on Systems. Volume II, ,WSEAS Press (GR), Rhodes, p.439-442.

[6] Carslaw, H., S., Jaeger, J., C. (2008) Conduction of Heat in Solids, Oxford: Clarendon Press.

[7] Kolomaznik, K. (1996) Theory of technological processes III, Brno: TU in Brno. (in Czech).

[8] Michal, P., Gombar, M., Vagaska, A., Pitel, J., Kmec, J. (2013) Experimental Study and Modeling of the Zinc Coating Thickness. Advanced Materials Research, Vol. 712-715 (2013), pp. 382-386. ISSN 1022-6680.

[9] Mizakova, J., Pitel, J., Hrehova, S. (2014) Some Simulation Results of Heat Transfer through the Wall Model. International Journal of Mathematical Models and Methods in Applied Sciences, Vol. 8 (2014), pp. 1-8. ISSN 1998-0140. 